\title{
A REVIEW ON THE PREVALENCE OF HYPERTENSION IN SIDE-LINED POPULATIONS; SLUM DWELLERS, SHIFT JOB WORKERS AND OCCUPATIONAL NOISE AFFECTED WORKERS: ATTRIBUTABLE TO LIFESTYLE AND ENVIRONMENTAL FACTOR
}

\author{
SANJEEV YADAV*, NIKITA SARASWAT, ARYENDU KUMAR SAINI, PRANAY WAL
}

Department of Pharmacy, Pranveer Singh Institute of Technology, Kanpur, Uttar Pradesh, India. Email: sanjeev019940@gmail.com

Received: 30 April 2018, Revised and Accepted: 06 June 2018

\section{ABSTRACT}

Hypertension is a condition that is characterized by the persistent raised blood pressure. It is not seen as a disease rather as a major risk factor that is solely responsible for different types of cardiovascular diseases such as heart failure, ischemic heart disease, and left ventricular hypertrophy. Although this condition cannot be cured, hypertension can be managed and prevented by adopting a healthy lifestyle that encompasses factors such as diet, physical exercise, reduced alcohol consumption, moderate sodium and potassium intake, and psychological factors. Apart from these, environmental factor like noise has also proved to be associated with the high blood pressure. Different prevalence studies have been conducted to find out the relationship between high blood pressure and different lifestyle factors. This article aims to review and emphasize the prevalence of high blood pressure in slum dwellers and at-risk workers who are shift job workers and occupational noise affected workers. Different research articles pertaining to different authors and countries have been reviewed to portray the concern of this condition. There is the need for proper recognition to these folks of people who are exposed to the precarious and high-risk style of living in the slum dwellers, shift job workers, and occupational noise affected workers. The distress in the physiological functioning of the body leading to hypertension has been found in the slum dwellers and at-risk workers; shift job workers and occupational noise affected workers that are again attributable to aforementioned lifestyle and environmental factor. The proper management of hypertension is extremely required to safeguard these unacknowledged groups of people.

Keywords: Hypertension, Slum dwellers, Noise, Blood pressure, Cardiovascular, Prevalence.

(c) 2018 The Authors. Published by Innovare Academic Sciences Pvt Ltd. This is an open access article under the CC BY license (http://creativecommons. org/licenses/by/4. 0/) DOI: http://dx.doi.org/10.22159/ajpcr.2018.v11i10.27007

\section{INTRODUCTION}

Hypertension is a very common disorder that is characterized by persistently raised blood pressure. The pressure is created by the force of blood against the walls of blood vessels that are arteries and veins [1]. It is not considered a disease in itself, but it acts as a major risk factor for different cardiovascular diseases (CVD), morbidity, and mortality. At an epidemic scale, diseases like hypertension are prevailing throughout the world due to various factors. The lifestyle pattern is one among them that has been elucidated in many patients. It is expected that by $2025,29 \%$ of the world's population will suffer from hypertension [2]. The updated World Health Organization-International Society of Hypertension (WHO-ISH) guidelines have defined the blood pressure to be $130 \mathrm{mmHg}$ of systolic blood pressure (SBP) and 80 $\mathrm{mmHg}$ or diastolic blood pressure (DBP) and it is this parameter for SBP and the DBP which has been used in many observational studies of prevalence of hypertension as a criterion for determining the people as a hypertensive [3].

The reason for considering the WHO-ISH guidelines as standard over the other guidelines like Joint National Committee 7 is that WHOISH guidelines are always aimed at the global audience, and it serves as a template for the development of regional, local, and national guidelines [4-7]. The adherence to proper medications and lifestyle is of utmost importance to achieve a therapeutic goal and will help to minimize the cardiovascular complications related to this condition [8]. Furthermore, in the WHO-ISH statement; there is no "prehypertension classification." Hypertension has been concretely related to the etiology of cerebrovascular disease, renal failure, cardiac failure, and ischemic heart diseases [9]. It became very clear from the review of articles that treating hypertension can confer different beneficial effects and in one such article, it was found that proper treatment can contribute to $40 \%$ reduction of risk of stroke and $15 \%$ reduction in the risk of myocardial infarction. The hypertension is responsible for $13 \%$ of deaths globally according to the WHO [10]. Furthermore, uncontrolled high blood pressure can damage the arteries that supply the blood to the heart muscle [11]. The increased blood pressure causes the heart to work harder than it normally pumps the blood. This causes the left ventricle to thicken over the time to cope up the increased pressure, the condition which is called as ventricular hypertrophy [10].

This hypertrophy can eventually lead to changes in the shape, size, and functions of the heart, the condition which is called as cardiac remodeling; which is life-threatening. Some other possible dangers of high blood pressure include osteoporosis; high blood pressure increases the amount of calcium that is excreted in the urine [11-13]. This excessive elimination ultimately leads to osteoporosis. It is very well known that the control of hypertension can enhance the quality of life, but its management is not adequate in many peculiar living conditions such as slums, shift job workers, and those exposed to the occupational noise.

The lifestyle factors and environmental factors play a very important role in determining the level of blood pressure [14]. Contrary to the previous conceptions that blood pressure depends only on the salt intake and stress, lifestyle factors such as body fat, alcohol consumption, potassium and sodium intake, physical activity, inadequate adherence to medicines, and psychological factors have been found to be associated with the blood pressure [10-14]. In the slums, there is the lack of basic necessities like food, drinking water, sanitation facility, and health care facility. On the premise of this, they have to live in the substandard conditions. They are exposed to the different types of disorders including hypertension. Many people of the slums have been found to be involved in drug dealing and street vending. The reason for this is attributable to the poverty and the high rate of unemployment.

There are many other populations besides these that require greater attentiveness, treatment, and care. This review article aims to highlight 
the pervasiveness of hypertension in three folks of people, namely slum dwellers and at-risk workers that are shift job workers and workers exposed to occupational noise through review of different observational studies that is the uniqueness and the novelty of this article since no other review article related to the objective of this review was found in the databases like PubMed comprising all the three side-lined folks together. There is the need for stringent laws that can protect these segments of individuals from this life-threatening condition.

\section{THE PREVALENCE OF HYPERTENSION IN THE SLUMS}

\section{The poor condition of people living in the slums}

The word "slum" had been first used in the London at the beginning of the $19^{\text {th }}$ century to describe a "room of low repute" or "the low, unfrequented parts of the town." The slum has been defined as "a contiguous settlement where the inhabitants are characterized as having inadequate housing and basic services" by the United Nations Program on Human Settlements [15]. In many places, the slums are not well recognized by the public authorities as an equal part of the city. The fast rate of urban growth has wrecked the provision of services and has led to the proliferation of informal settlements that are the development of the smaller cities without the access to basic necessities such as water, sanitation, and other infrastructural facilities [16-18]. The people living in the urban slums are not only prone to communicable diseases but also to non-communicable diseases like hypertension. In addition to diseases, they are also exposed to harmful diets, obesity, alcohol, and tobacco use, most of this unhealthy lifestyle can be attributed to the poverty, less access to the medical facilities and lack of education and awareness [19].

\section{Observational studies related to the prevalence of hypertension in slums}

The prevalence of hypertension in different observational studies involving the slums has been reviewed that certifies the fact that people in slums are suffering from hypertension and CVD. The criteria set for calling a person as a hypertensive is a SBP of $\geq 140 \mathrm{mmHg}$ and DBP of $\geq 90 \mathrm{mmHg}$ as stated by the WHO/ISH guidelines. In a hypertension prevalence and associated factors study conducted by Daniel et al. in the slum area of Ajegunle in the Lagos state of Nigeria on the 964 respondents of the mean age of $40.27 \pm 13.8$ in the case of males and $37.50 \pm 12.3$ in case of females, it was found that the overall prevalence of the hypertension was $38.2 \%$. Of this, the prevalence of systolic hypertension and the diastolic hypertension was the $37.1 \%$ and $14.5 \%$, respectively. The mean SBP was found to be $136.96 \pm 25.2 \mathrm{mmHg}$ and mean DBP was found to be $75.94 \pm 14.42 \mathrm{mmHg}$. The proportion of males and females differed significantly in terms of systolic and diastolic hypertension, proportion of males with the diastolic hypertension was less than females that is $13.3 \%$ as compared to $15.1 \%$; $(\mathrm{p}=0.5)$ while the proportion of the females having the systolic hypertension was found to be less than that of males that are $33.8 \%$ of females and $43.6 \%$ of males; ( $\mathrm{p}=0.003$ ). Of 368 participants of the study having hypertension, only 50 individuals were found to be aware of their diagnosis while 318 individuals were not aware of the diagnosis. The study further presented that prevalence of the hypertension was greater with the age. This was evident from the fact that there was a rise in the prevalence rate from $13 \%$ in the males of the age group between 20 and 29 years to $80 \%$ in the males of the age group $>60$ years [20].

Another study which was a cross-sectional study conducted by the Dhikale et al. on the people living in the Malwani slum area of Mumbai, which included 540 males and 549 females, the prevalence of the hypertension was found out to be $257(23.59 \%)$, of which prevalence of hypertension in the males was $23.15 \%$ and females was $24.04 \%$. The study involved the people of the age group of 18-30 years. Of these 257 hypertension patients, only 107 patients were aware of the fact that they had hypertension and out of these patients, only 59 patients were taking the treatment. The mean systolic and the diastolic pressure of the hypertensive patients were found out to be $146.4 \pm 2.6 \mathrm{mmHg}$ and 107.4 $\pm 2.6 \mathrm{mmHg}$ [21]. A cross-sectional study to find the prevalence of hypertension in the slums in and around the urban field area of Bangalore Medical College and Research Institute was conducted by the Shivraj et al. A total of 1306 patients took part in the study of which 255 patients were males and 1051 patients were females. The mean age was $51.88 \pm 20$ years. Here, the prevalence was found out to be $39.58 \%$. The hypertension was found out to be more associated with the increasing age, higher body mass index (BMI), and tobacco consumption [22].

A population-based cross-sectional study was reviewed that was conducted in the slums of Kolkata in cooperation with Kolkata Municipality Corporation. In this study by Banerjee et al., a total of 10,175 adult individuals were enrolled of which analyzable data were available for only 10,167 , individuals age was $\geq 20$ years. Out of 10,175 adult individuals, 4079 (40.1\%) were males and 6088 (59.9\%) were females.

The overall prevalence was found to be $42 \%$, and the prevalence was found to be higher in men than in women that were $47 \%$ for men and $39 \%$ for women. In $19 \%$ of the population, hypertension was newly detected. $54 \%$ of hypertensive individuals were found to be aware of their hypertension status, 38\% were found to be on antihypertensive treatment, and $12 \%$ of people were found to have their BP controlled to the target level. The prevalence of hypertension was seen higher in men, people above 60 years of age, minority community, and tobacco users [23]. It has been found that the increase in the number of elderly contributes to an increase in the prevalence of hypertension and this can be seen from a cross-sectional study by Singh et al. which included the elders of the urban slum of Delhi, India. A total of 496 people were involved in this study of which there were 258 men and 238 women. The mean age was $65.1 \pm 6.4$ years. The prevalence of hypertension in elderly was found to be $39.5 \%$ (95\% confidence interval: $35.2-49.0$ ). It was $36.4 \%$ and $42.9 \%$ in men and women, respectively. The mean systolic and diastolic pressure was found to be $122.4 \pm 8.9 \mathrm{mmHg}$ and $78.4 \pm 5.2 \mathrm{mmHg}$, respectively. The mean SBP and DBP were found to have risen with age. Only $28.6 \%$ of hypertensive people were aware of their condition. This awareness was higher in women than in men; ( $35.3 \%$ in women and $21.3 \%$ in men). Out of 196 people who were found to be hypertensive, $34(17.3 \%)$ were getting the treatment, and $18(9.2 \%)$ had controlled blood pressure [24]. Another crosssectional study was done involving the people of the 24 slums of North 24 Parganas district of West Bengal. $20 \%$ of the population in North 24 Parganas lives in the slums. This study was carried out by the Acharya et al. to find the prevalence of hypertension apart from the prevalence of behavioral risk factors and overweight. A total of 1052 participants in 24 slums were involved in the study and the age group of 25-64 years was involved. The proportion of males and females in the study was $528(50.2 \%)$ and $524(49.8 \%)$, respectively. The number of hypertensive individuals and the prevalence of hypertension in males and females were $185(35 \%)$ and 175 (33\%), respectively. Those found with hypertension, $93(50.2 \%)$ in case of males and $73(41.7 \%)$ in case of females had newly detected hypertension.

The overall prevalence of hypertension was $34.2 \%$ that means a total of 370 individuals had hypertension. In this study too, the hypertension was found to be high in the age group of 45-64 years than 25-44 years of age group [25]. A study was reviewed which was found to be a crosssectional study and was conducted in Nandgiri by Panesar et al. which is a slum resettlement area in East Delhi, India. The people having the age of 20-59 years were included in the study.

The total number of people who were enrolled in the study was 310 . Of the 310 individuals, females were higher in number than the males, presenting $52.9 \%$ as compared to males, only $47.1 \%$. The overall prevalence was found to be $17.4 \%$, and the prevalence in males and females was found to be $17.8 \%$ and $17.1 \%$. As the age advanced, the prevalence also found to be increased and was higher in case of 5059 years with $36.6 \%$ [26]. Another cross-sectional study was found during the literature search which had been done in the selected slums 
of urban field practice of Osmania Medical College, Hyderabad. This cross-sectional study was conducted by Kumari et al. They included a total of 700 participants as a sample size. Among these participants, a total of 185 (26.4\%); 85 males and 100 females were found to have hypertension. The prevalence of hypertension in the males was $24.6 \%$ while in the females, it was $28.2 \%$ [27]. Furthermore, it was also found to be prevalent in the Sub-Saharan African countries including Ghana. A prevalence study that was cross-sectional type was conducted in the urban poor communities of Accra, Ghana by Awuah et al. It included the young adult population who were in their reproductive age. A total of 714 young adults were surveyed of which women were 15-49 years of age and males were comprised 15-59 years of age. The total prevalence was found to be $28.3 \%$. Of this prevalence, women comprised $25.6 \%$ and men comprised $31 \%$. A total of $7.4 \%$ of individuals were aware of their condition, and $4 \%$ were found to be on the antihypertensive medicines. The level of treatment and awareness was higher in the woman than in the men [28]. This prevalence clearly elucidates the need for health-care programs like Community Based Health Planning and Services program.

In Ansan city of South Korea, a cross-sectional study was performed to find out the prevalence of hypertension in the people of that city by Jo et al. A total of 2278 men and 1948 women were selected and for being called as a hypertensive, a SBP of $\geq 140 \mathrm{mmHg}$ and a DBP of $\geq 90 \mathrm{mmHg}$ criteria were set. The overall prevalence of hypertension in the people aged $18-92$ years was found to be $33.7 \%$.

The hypertension prevalence was found to be higher with the increasing age that was $14.19 \%$ in the people $18-24$ years of age, and it was found to be $71.39 \%$ in the people above the age of 75 . The prevalence in men was $41.5 \%$ and women was $24.5 \%$. Hence, greater was the prevalence in the males than in females [29].

Another prevalence study was reviewed, and this was conducted in the Canada Provinces. It was conducted by the Jofress et al. and was a cross-sectional study. A total of 26,293 comprising of both men and women were included in this study. The age criteria set in this study was 18-74 years. The overall prevalence of hypertension in the study was $29 \%$. Of this prevalence, $16 \%$ of men and $13 \%$ of women had hypertension. Around $26 \%$ were found to be unaware of their hypertension. Furthermore, in the study, it was seen that high prevalence of blood cholesterol, sedentary lifestyle, and high BMI was there in the hypertensive patients than in normotensive [30].

The overall prevalence of hypertension besides other parameters in different slums of the countries such as India, Nigeria, Ghana, and Canada has been summarized in Table 1 .

\section{INFERENCE}

The prevalence of hypertension is high in the slum areas of different parts of the world. The cross-sectional studies and other observational studies for finding the prevalence of hypertension have revealed that prevalence has increased with age, being more in the people of old age. Besides, widespread hypertension was found to be equally prevalent in both males and females. The poor living conditions, poor water supply, and improper sanitation have presented the slums people with different diseases. Moreover, it was also found that prevalence was high in the people of slums who were tobacco users and alcohol consumers and was not well aware of their disease status. This unawareness can be definitely attributed to the poverty and the lack of education.

\section{HYPERTENSION ASSOCIATED WITH SHIFT JOBS}

\section{Altered body physiological processes due to shift jobs}

The shift jobs, especially the night shift jobs are associated with the disturbances of the sleep-wake cycle which is a well-coordinated process that involves the rhythmic changes in the sensory, autonomic, motor, endocrine, and cerebral process [31]. The sleep-wake cycle like other circadian rhythms is strongly under the influence of melatonin hormone which is secreted by the pineal gland [32]. The secretion of the pineal gland, in turn, is regulated by the suprachiasmatic nucleus (SCN). In the early 1970s, the field of circadian biology and behavioral state regulation started to overlap, and sets of observations were found.

It was demonstrated that retinohypothalamic tract terminates in the SCN of the hypothalamus and found to be critical to the entrainment of circadian rhythms. When the SCN was ablated, it resulted in the loss of endocrine rhythms and behavioral rhythms [33]. A SCN is a small group of hypothalamic nerve cells that act as a master circadian pacemaker and controls the timing of sleep-wake cycle.

Shift jobs are well found to have prevailed with hypertension and the studies verifying the fact that shift jobs workers have altered physiological processes [34].

Disturbances in the circadian rhythm of the autonomic nervous system and neurohumoral factors have been seen in a study on the people who do not take the proper sleep [35]. The autonomic nervous system and neurohumoral factors play a crucial role in the peripheral and central regulation of blood pressure, and when there is the alteration in these factors, there will be the alteration in the typical 24-h blood pressure pattern [36]. Moreover, the alteration in the light and darkness that are the environmental factors, in conjunction with the sleep-wake cycle, influence the day-night pattern of catecholamines concentration in the blood. Although the circadian rhythms follow a 24-h pattern and are mostly regulated by the internal factors, external factors like light also influence the sleep-wake cycle [37]. The sleep-wake cycle usually results from the alteration from the mutually inhibitory interaction of activating system (serotonergic, cholinergic, and histaminergic neurons of the rostral pons, midbrain, and posterior hypothalamus). In parallel to the activating system, the deactivating system that consists of adjacent basal forebrain, medulla, medial thalamus, and medial pre-optic anterior hypothalamic region also plays an important role

Table 1: Prevalence of hypertension in different prevalence studies along with other parameters

\begin{tabular}{|c|c|c|c|c|c|c|c|c|}
\hline S. No & $\begin{array}{l}\text { Conducted by } \\
\text { researchers }\end{array}$ & $\begin{array}{l}\text { City/Country } \\
\text { of slums }\end{array}$ & $\begin{array}{l}\text { Total number } \\
\text { of subjects }\end{array}$ & $\begin{array}{l}\text { Total number } \\
\text { of subjects found } \\
\text { with hypertension }\end{array}$ & $\begin{array}{l}\text { The overall prevalence } \\
\text { of hypertension }(\%)\end{array}$ & $\begin{array}{l}\text { Prevalence } \\
\text { in males (\%) }\end{array}$ & $\begin{array}{l}\text { Prevalence } \\
\text { in females (\%) }\end{array}$ & References \\
\hline 1 & Panesar et al. & Nandgiri/India & 310 & 54 & 17.4 & 17.8 & 17.2 & {$[20]$} \\
\hline 2 & Dhikale et al. & Mumbai/India & 1089 & 257 & 23.6 & 23.15 & 24.04 & [21] \\
\hline 3 & Kumari et al. & Hyderabad/India & 700 & 185 & 26.4 & 24.6 & 28.2 & [27] \\
\hline 4 & Awuah et al. & Accra/Ghana & 714 & 202 & 28.3 & 25.6 & 31 & [28] \\
\hline 5 & Joffres et al. & Canada & 26293 & 7624 & 29 & 16 & 13 & [30] \\
\hline 7 & Acharya et al. & West Bengal/India & 1052 & 370 & 34.2 & 35 & 34.2 & [25] \\
\hline 8 & Daniel et al. & Lagos/Nigeria & 964 & 368 & 38.2 & NA & NA & [26] \\
\hline 9 & Singh et al. & Delhi/India & 496 & 196 & 39.5 & 36.4 & 42.9 & [24] \\
\hline 10 & Shivraj et al. & Bangalore/India & 1306 & 1424 & 39.58 & NA & NA & [22] \\
\hline 11 & Banerjee et al. & Kolkata/India & 10175 & 4273 & 42 & 47 & 39 & [23] \\
\hline
\end{tabular}

$\mathrm{NA}=$ Not available 
in controlling the sleep-wake cycle. Cyclic variations in the autonomic nervous system have been found to play a role in the mechanism of the sleep-wake cycle and the mediation of cardiovascular function and blood pressure [36]

\section{Observational studies associated with a prevalence of hypertension and shift jobs}

Different observational studies found the association and the prevalence of high blood pressure in the people doing shift-jobs. A study that was a cross-sectional, conducted by Nazri et al., included 148 randomly selected male workers from a factory in the Kota Bharu, Kelantan (Malaysia) to establish a link between the shift work and hypertension showed that the prevalence of hypertension was higher among the shift workers, $22.4 \%$ and it was $4.2 \%$ in day workers. The study concluded that there is a significant and reasonable association between the shift job and hypertension [37]. In one another study that was conducted to find out the association between the shift job and hypertension. The study was performed by Asfaw et al. in Wonji Shoa Sugar Factory that was one of the oldest factories in Ethiopia. The participants were the employees of the factory who had been working for 6 years. The final number of participants that were included in the study was 830 of which 413 were shift workers, and 417 were day workers. The criterion for declaring the participant as a hypertensive was SBP $>140 \mathrm{mmHg}$ and DBP >90 mmHg. All the shift workers were found to be working 3 shifts rotating every week. The overall prevalence of hypertension in the participants was found to be $36.4 \%$. The prevalence of hypertension in the shift workers was found to be higher than the day workers that is $177(42.9 \%)$ in shift worker and 125 (30\%) in day workers. In this study, hypertension was found to be higher in males than in females (38.1\% in males and $28.5 \%$ in females). It was also found out that prevalence was high in the old age people, that is, who were above the age of 50 years, prevalence was $54.1 \%, 49.3 \%$ in daytime workers, and $57.1 \%$ in shift workers [38]. A cross-sectional study was conducted using the questionnaires and health examination of male workers at a petrochemical plant in South Korea. It was conducted by Yeom et al. to find out the association between the shift work and hypertension.

Of total 2333 workers, a total of only 1953 male workers were selected for final analysis. Of these, 878 were found to be day workers, and 1075 were found to be shift workers. The results of the study showed that shift workers have significantly higher SBP and DBP that is $122.4 \mathrm{mmHg}$ and $73.7 \mathrm{mmHg}$ than those who were day workers that is $\mathrm{SBP}=121 \mathrm{mmHg}$ and $72.2 \mathrm{mmHg}$ DBP.

From the prevalence point of view, the prevalence of hypertension in shift workers was $12.2 \%$ and in the day workers, it was found to be $9.6 \%$. In addition to hypertension, shift work was also found to be associated with metabolic disorders like diabetes due to the disruption in the circadian rhythm [39].

Hypertension associated with the shift jobs has been seen in many studies. One such study was conducted by Pimenta et al. It was a crosssectional epidemiological study that was conducted on the employees of health science campus of a public university in the state of Minas Gerais, Brazil. The age of individuals was between 30 and 65 years. A total of 211 workers were included in this study consisting of both genders. The study contained $37.9 \%$ male and $62.1 \%$ female.

The exposure variable was the work shift that is day shift (between 7 am and $7 \mathrm{pm}$ ) and night shift ( $7 \mathrm{pm}$ and $7 \mathrm{am})$. Out of the total participants, $61.6 \%$ performed their duties on the day shift and $34.8 \%$ did their activities on the night shift. A total of $27.5 \%$ of the total sample were diagnosed with hypertension. $37 \%$ of the night shift workers were found to have high cardiovascular risk than day shift workers, who contributed $22.3 \%$. The prevalence of CVD risk was found to be higher in the night shift workers (67\%) higher than day shift workers. Apart from these, systolic and diastolic pressure above 160 and 100 was found in $13.6 \%$ of night shift workers than $6.9 \%$ of night workers [40]
A prospective cohort study involving the Japanese 6495 male workers from a Japanese steel company was conducted to find out if the shift work affects the progression of hypertension by Oishi et al. This study included all those male workers who had mild hypertension that is SBP (140-160 mmHg) and DBP (90-99 mmHg). Three different shifts, namely day shift, evening shift, and night shift were considered. The clinical endpoint in the study was severe hypertension or systolic or diastolic hypertension, SBP $\geq 160 \mathrm{mmHg}$ and/or $\mathrm{DBP} \geq 100 \mathrm{mmHg}$. Out of the total participants of the study, 504 (17.3\%), 695 (23.6\%), and $559(19.2 \%)$ developed the severe systolic hypertension, severe hypertension, and severe diastolic hypertension. Hence, job schedule was highly associated with the progression from mild hypertension to severe hypertension [41].

Another cohort study was reviewed by the author that was conducted to investigate the relationship between the shift work and hypertension by Morikawa et al. This study included the workers of aluminum slash and zipper factory in Japan. 1551 men of age between 18 and 49 years were prospectively followed for a period of 5 years. The cumulative incidence of hypertension in 3-shift workers was compared with day workers. The shift workers were found with higher mean SBP and DBP. The relative risk of the rotating 3-shift during the observational period was found to be increased when it was compared with day workers. Of the 1551 subjects, 109 found to have the onset of hypertension, and the cumulative incidence of all the subjects was found to be $7 \%$.

The workers who aged between the 18 and 29 years and who did shift-shift work had the cumulative incidence of hypertension that is $11.9 \%$. Similarly, in the people of other age groups such as 30-39 and 40-49 years, the cumulative incidence of hypertension was found to be higher in the people who did shift work [42]. Table 2 shows the prevalence of hypertension along with other information related to shift job workers.

\section{INFERENCE}

It is very clear from the above observational studies that prevalence of hypertension does have the association with shift jobs, especially the night shift job. The main reason responsible for hypertension is that the people doing the shift jobs have a disrupted circadian rhythm which maintains the sleep-wake cycle, and circadian rhythm mediates the influence of sleep and wakefulness on blood pressure. It can be inferred from the study by Yeom et al. that prevalence of the metabolic disorder is high besides hypertension like diabetes in night shift job workers. In addition to this, it was found that prevalence in workers of shift jobs above the 50 years of age is high as compared to those below 50 years. The risk of CVD is also high in the night shift job workers.

\section{OCCUPATIONAL NOISE AND THE PREVALENCE OF HYPERTENSION}

\section{Noise health effects}

Noise is the sound that is unwanted, loud, and can cause disturbances. It represents the fluctuations in the pressure of the air that affects the body. The occupational noise can be defined as the amount of acoustic energy that is received by the auditory system of the employee while working in the industry [43]. Although people are habituated to noise exposure, the degree of this habituation differs greatly among the individuals. If this exposure to noise is chronic and found to be exceeding above a certain level, then harmful effects on health are seen. The major impact of occupational noise on the human health is the psychological and physiological effects. The most sought nonauditory effects are cognitive impairment, sleep disturbance, annoyance, and CVD [44]. Both the short-term and long-term animal studies have given the biological mechanisms and rationality for the theory that chronic exposure to environmental noise affects the cardiovascular system and manifests as hypertension, stroke, and ischemic heart disease [45-47]. When it comes to physiological effects, the dysfunctional stress mechanisms majorly prevail. Hypertension is a medical condition that is characterized by elevated blood pressure in the arteries. Hypertension has been comparatively prevailing as one of the conditions and risk 
Table 2: Different studies involving shift job workers with the prevalence of hypertension

\begin{tabular}{|c|c|c|c|c|c|c|c|}
\hline S. No & $\begin{array}{l}\text { Conducted } \\
\text { by researchers }\end{array}$ & Study type & $\begin{array}{l}\text { Place of } \\
\text { conducting study }\end{array}$ & $\begin{array}{l}\text { Number of } \\
\text { participants } \\
\text { enrolled }\end{array}$ & $\begin{array}{l}\text { Number of participants } \\
\text { found with } \\
\text { hypertension }\end{array}$ & $\begin{array}{l}\text { The overall } \\
\text { prevalence } \\
\text { of hypertension }(\%)\end{array}$ & References \\
\hline 1 & Nazri et al. & Cross-sectional & Malaysia & 148 & 33 & 22.4 & [37] \\
\hline 2 & Asfaw et al. & Cross-sectional & Ethiopia & 830 & 302 & 36.4 & [38] \\
\hline 3 & Yeom et al. & Cross-sectional & South Korea & 2333 & 284 & 12.2 & [39] \\
\hline 4 & Pimenta et al. & Cross-sectional & Brazil & 211 & 58 & 27.5 & [40] \\
\hline 5 & Oishi et al. & Prospective Cohort & Japan & 6495 & 1532 & 23.6 & [41] \\
\hline
\end{tabular}

factors for CVD in the workers exposed to the noise. The most probable mechanism that justifies the relationship between the noise and hypertension is the release of stress hormones such as cortisol and the stimulation of sympathetic nervous system to release the greater amount of epinephrine and norepinephrine.

The auditory system is associated with the neuroendocrine system and sympathetic nervous system and reacts to sound stimulus through reflexes which is evident from cardiovascular effects, for instance, changes in the level of steroidal hormones and catecholamines, and changes in the heart rate $[48,49]$.

The chronic exposures are responsible for the imbalance of the people's homeostasis, because of which the cardiovascular system and metabolism are affected. It has also been found that the risk factors of CVD get increased such as blood lipid concentrations, blood viscosity, and blood glucose concentration. Different experimental and occupational epidemiological studies have suggested higher prevalence and incidence of CVD and mortality in a highly exposed group. A study by Sudo et al. demonstrated that stress hormones level was higher in the exposure group to noise than the nonexposure group [50]. In addition to hypertension, hearing loss is also largely associated with the occupational noise exposure, and it progresses over the years. Exposure to noise is generally measured in the units of sound pressure levels which is called as decibels (dBs). $\mathrm{A}$-weighted $\mathrm{dB} \mathrm{A}$ is the most appropriate and generally measured for the occupational noise.

In spite of the standards set for hearing protection, hearing loss due to occupational noise is still a thing of concern. This can be certified from the fact that about 22 million United States (US.) workers get exposed to deleterious or hazardous noise levels at work. An estimated amount, US\$ 242 million is spent as compensation to the workers for the noisecaused hearing loss. An exact level of noise exposure in the industries that can have the hearing damage potency is internationally debated. For instance, in the United Kingdom (UK), the set levels of noise are $80 \mathrm{~dB}$ (at which protection is made available) and $85 \mathrm{~dB}$ (at which protection is made mandatory). It was found in 3 years follow-up the study of 19 companies of United Kingdom said that the values were safe. Similarly, U.S. has its own standards for the noise level set by the agency, Occupational Safety and Health Administration (OSHA). The hearing loss is considered to be low at exposure below $85 \mathrm{~dB}$ for $8 \mathrm{~h}$. OSHA has given the standards and regulations for noise at the workplace and has agreed that noise becomes hazardous when it exceeds $85 \mathrm{~dB}$ for an $8 \mathrm{~h}$ time exposure [51].

Observational studies related to the prevalence of hypertension in occupational noise-induced workers

During the review of original articles, it became very much clear that there is the association between the noise and prevalence of hypertension. A study was done at the Guangzhou Number 12 people hospital, China by Shrestha A et al. this study included a total number of 274 people of the steel factory. Inclusion criteria for this study were the involvement of those individuals who had exposure to noise for more than 1 year, and the noise exposure intensity must be more than $80 \mathrm{~dB}$. The cumulative noise exposure was associated with hypertension $(p=0.004)$. The hypertension criterion set for the workers was according to the WHO which was SBP $\geq 140 \mathrm{mmHg}$ and $\mathrm{DBP} \geq 90 \mathrm{mmHg}$. Total prevalence of hypertension in this study was found to be $9.8 \%$, and this prevalence was in the workers who were under the noise $>90 \mathrm{~dB}$. The prevalence was found to be highly influenced by the BMI overweight [52].

Another cross-sectional study was carried out on 1205 workers who were exposed to different levels of noise by Pang et al in China. The study aim was to find the prevalence and the influential factors of hypertension in the mechanic factory workers. The prevalence of the hypertension was found to be $12.1 \%$. Apart from the accumulative noise level that influenced the prevalence of hypertension, logistic regression analysis showed that the body weight index (BMI) and age were also influential [53].

A cross-sectional study was performed by Talbott et al. to study the noise exposure and high blood pressure in a group of blue-collar workers from a noisy and a less noisy plant. The study was conducted in the city of Pittsburgh, United States. The noisy plant had $\geq 89 \mathrm{~dB}$ and the less noisy plant had $<81 \mathrm{~dB}$. A total of 197 men were selected randomly from the noisy plant and 169 from the less noisy plant which served as the comparison group. A strong relationship was found between the severe noise-induced hearing loss and high blood pressure in the people of higher than 56 years of age. The overall prevalence of hypertension was found to be $47.4 \%$, and this percentage of individuals was also found to have the hearing loss [54].

A cross-sectional study was conducted by Chang et al. in central Taiwan. They used hearing loss values that are measured at $4 \mathrm{kHz}$ and $6 \mathrm{kHz}$ (kilohertz) in both the ears to serve as a biomarker for investigating the chronic effects of noise on hypertension in 790 individuals.

These participants were composed of production line workers. To investigate the association between the noise exposure and prevalence of hypertension, hearing loss quantified bilaterally at $4 \mathrm{KHz}$ and $6 \mathrm{KHz}$ was used as a biomarker for environmental noise exposure to classify the subjects into three groups, namely high hearing loss group $(n=214$ and average $\mathrm{HLV}>30 \mathrm{~dB}$ at $4 \mathrm{~Hz}$ or $6 \mathrm{~Hz}$ bilaterally), median hearing loss group ( $\mathrm{n}=302$ and average $\mathrm{HLV}<30 \mathrm{~dB}$ at $4 \mathrm{~Hz}$ or $6 \mathrm{~Hz}$ bilaterally), and low hearing loss group ( $\mathrm{n}=274$, and average $\mathrm{HLV}<15 \mathrm{~dB}$ at $4 \mathrm{~Hz}$ or $6 \mathrm{~Hz}$ bilaterally). A significant difference was noted in the three groups with respect to hypertension. The prevalence was $43.2 \%$ in high hearing loss group, prevalence was $42.1 \%$ in median hearing loss group, and prevalence was $33.2 \%$ in low hearing loss group [55].

A study was conducted that involved a total of 7901 workers belonging to small and medium-sized companies of the Paris area. The study was conducted by Lang et al. [56]. These companies were mechanical or chemical industries. The level of noise that was set as the criterion at the work site was $\geq 85 \mathrm{dBA}$. The criteria set for classifying workers as hypertensive was SBP $\geq 160 \mathrm{mmHg}$ and $\mathrm{DBP} \geq 95 \mathrm{mmHg}$. Of 7901 , the data of 7679 were available. Mean age was $38.8 \pm 11.2$ years and BMI was $23.9 \pm 3.8 \mathrm{~kg} / \mathrm{m}^{2}$. Total men and women who were found to be hypertensive were 709 and 363, respectively. Hence, the overall prevalence was found to be $14 \%$. Those who were exposed had higher 
Table 3: Total prevalence of hypertension in workers exposed to occupational noise in different studies

\begin{tabular}{|c|c|c|c|c|c|c|}
\hline S. No & $\begin{array}{l}\text { Conducted by } \\
\text { researchers }\end{array}$ & $\begin{array}{l}\text { Country } \\
\text { of the study }\end{array}$ & $\begin{array}{l}\text { Total number } \\
\text { of workers }\end{array}$ & $\begin{array}{l}\text { Total number } \\
\text { of workers found with hypertension }\end{array}$ & $\begin{array}{l}\text { Total prevalence } \\
\text { of hypertension (\%) }\end{array}$ & References \\
\hline 1 & Shrestha A et al. & China & 274 & 27 & 9.8 & {$[52]$} \\
\hline 2 & Pang et al. & China & 1205 & 145 & 12.1 & [53] \\
\hline 3 & Talbott et al. & United States & 169 & 80 & 47.4 & [54] \\
\hline 4 & Chang et al. & Central Taiwan & 790 & 341 & 43.2 & [55] \\
\hline 5 & Lang et al. & Paris & 7679 & 1075 & 14 & [56] \\
\hline 6 & Parvizpoor D & Iran & 821 & 70 & 8.5 & [57] \\
\hline
\end{tabular}

SBP as compared to unexposed. This was also same for DBP. BMI was found to be higher in the exposed person that was $\left(24.3 \pm 4 \mathrm{~kg} / \mathrm{m}^{2}\right)$ as compared to non-exposed $\left(23.9 \pm 4 \mathrm{~kg} / \mathrm{m}^{2}\right)$.

Finally, a study by Parvizpoor was reviewed which emphasized the need for periodic examination of the blood pressure of the workers who are working in the noisy conditions. This study was conducted in Iran and involved the weavers. Three textile mills got chosen randomly from a total of 20 mills with more than 200 employees. Of all, 821 weavers were selected. The average noise level at all the three textile mills was found to be $96 \mathrm{dBA}$ without any significant variations. Those workers were considered as hypertensive that had the SBP of $160 \mathrm{mmHg}$ or more and the DBP of $95 \mathrm{mmHg}$ or more, and this criterion was set according to the recommendations of the WHO expert committee. The total prevalence was found to be $8.5 \%$. In this study, a clear association between the length of employment and prevalence of hypertension was seen, being highest (26.1\%) in the people who were employed for more than 20 years as compared to other workers who worked for $<10$ years [57]. The summarized prevalence found in different studies along with other relevant variables is given in Table 3 .

\section{INFERENCE}

Different studies like cross-sectional studies reveal that there is the definite association between hypertension and occupational noise exposure. After having inferred Table 3, it is very clear that people who were exposed to the noise had hypertension; the highest prevalence of hypertension was found to be the highest in the study conducted by Talbott et al. being $47.4 \%$ and the counterpart that is the lowest prevalence was found in the study conducted by Parvizpoor. These values clearly depict the relationship between hypertension and noise. The prevalence has been also found to be dependent on the length of exposure to noise or the length of employment as seen in the last study by the Parvizpoor Studies have successfully shown that deregulation of stress hormones takes place in the people exposed to above $85 \mathrm{db}$. Hearing loss due to noise is another problem that is accompanied by hypertension. The proper monitoring of noise levels and strict adherence to regulatory agencies standards for the regulation of noise levels at the workplace is the need.

\section{CONCLUSION}

The lifestyle and environmental factors play a key role in the commencement and progression of different diseases. The noncommunicable disease, hypertension is a substantial risk factor for different CVD. The pervasiveness of hypertension has been found in three groups of people that are the people living in the slums, the people who are doing the shift jobs, and in the people who are exposed to the occupational noise. The prevalence in the slum dwellers and shift jobs workers are related to the lifestyle factors, and the third group can be related to the environmental factor, noise. The people in the slums have low access to health-care facilities, most of them are unaware of the disease, and treatment rates are less. Implementation of the strategies like free health education related to diseases such as hypertension, making the availability of basic necessities to improve their living conditions, and proper recognition of these side-lined populations is necessary. The second group of people, shift jobs employees, is also prevailed with hypertension. Shift work is definitely a risk factor for increased blood pressure. There is the need for the proper adherence to the national and social measures that can safeguard the health and can provide the quality life to the shift workers. The same holds true for the workers who are exposed to the occupational stress, proper monitoring of noise levels in accordance with the regulatory agencies standards is the alarming need.

\section{ACKNOWLEDGMENT}

The authors are thankful to the Pharmacy Department of Pranveer Singh Institute of Technology, Kanpur, Uttar Pradesh, India, who helped us a lot while writing this review article.

\section{AUTHORS' CONTRIBUTIONS}

All authors have substantially contributed in writing of this review article. Ms. Nikita Saraswat who is the second author has played a crucial role in this article. She suggested the topic and helped in acquisition, and interpretation of the data in the article. The first author, Mr. Sanjeev Yadav has done the literature review and searched the most relevant articles for the review. The third author, Mr. Aryendu Kumar Saini has revised the article critically for its intellectual content and helped in the final approval of the version to be published. The last author who is Dr. Pranay Wal is our Dean (R \& D) of P.S.I.T. without the guidance of whom this article would not have been possible.

\section{CONFLICTS OF INTEREST}

There are no conflicts of interests.

\section{REFERENCES}

1. Kannan A, Janardhanan R. Hypertension as a risk factor for heart failure. Curr Hypertens Rep 2014; 16:447.

2. Burns J, Sharma DP, Green D. Beyond JNC 8: Implications for evaluation and management of hypertension in underserved populations. Acta Cardiol 2018;1:1-8

3. Whelton PK, Carey RM, Aronow WS, Casey DE, Collins KJ, Himmelfarb CD, et al. Guideline for the prevention, detection, evaluation, and management of high blood pressure in adults. J Am Coll Cardiol 2017;12:1-73.

4. Liman DP, Mulla A, Pawar S, Diwan A. An overview of rational prescribing pattern in hypertensive patients in tertiary care hospital. Int J Pharm Pharm Sci 2016;8:273-6.

5. Cabandugama PK, Gardner MJ, Sowers JR. The renin angiotensin aldosterone system in obesity and hypertension. Med Clin 2017;101:129-37.

6. Blankestijn PJ, London G, Fliser D, Jager KJ, Lindholm B, Goldsmith D, et al. Major pathways of the reno-cardiovascular link: The sympathetic and renin-angiotensin systems. Kidney Int Suppl 2011;1:13-6.

7. Carter BL. Implementing the new guidelines for hypertension: JNC 7, ADA, WHO-ISH. J Manag Care Pharm 2004;10:S18-25.

8. Drodz D, Jaszcz KK. Cardiovascular changes during chronic hypertensive states. Pediatr Nephrol 2014;29:1507-16.

9. Moser M. Update on the management of hypertension: Recent clinical trials and the JNC 7. J Clin Hypertens (Greenwich) 2004;6:4-13.

10. Agbor BB, Setaro JF. Management of Hypertension in Patients with Ischemic Heart Disease. Curr Cardiol Rep 2015;17:119.

11. Azevedo PS, Polegato BF, Minicucci MF, Paiva SA. Cardiac remodeling: Concepts, clinical impact, pathophysiological mechanisms and pharmacologic treatment. Arq Bras Cardiol 2016;106:62-9. 
12. Shukla R, Omray LK. Formulation and Characterization of diltiazem transdermal system for the treatment of hypertension. Int J Curr Pharm Res 2016;8:12-5

13. Nakagami H, Morishita R. Hypertension and osteoporosis. Clin Calcium 2013;23:497-503.

14. Beilin LJ, Puddey IB, Burke V. Lifestyle and hypertension. Am J Hypertens 1999;12:934-45.

15. Yang MH, Kang YS, Lee AH, Kim YS, Sung EJ, Lee KY, et al. The effect of lifestyle changes on blood pressure control among hypertensive patients. Korean J Fam Med 2017;38:173-80

16. Jhawat V, Gupta S, Agarwal BK, Roy P, Saini V. Prevalence and risk factors of essential hypertension and new onset of diabetes in essential hypertension in rural population of Haryana. Int J Pharm Pharm Sci 2018;10:142-8.

17. Garg A, Anand T, Sharma U, Kishore J, Chakraborty M, Rai B, et al. Prevalence of risk factors for chronic non-communicable diseases using WHO steps approach in an adult population in Delhi. J Family Med Prim Care 2014;3:112-8

18. Rashid FS. Strategies to reduce exclusion among populations living in urban slum settlements in Bangladesh. J Health Popul Nutr 2009;27:574-86

19. Nolan LB. Slum definitions in Urban India: Implications for the measurement of health inequalities. Popul Dev Rev 2015;41:59-84.

20. Daniel OJ, Adejumo OA, Adejumo EN, Owolabi RS, Braimoh RE. Prevalence of hypertension among urban slum dwellers in Lagos, Nigeria. J Urban Health 2013;90:1016-25.

21. Dhikale PT, Solanki MJ, Shrivastava SR. A study of epidemiology of hypertension in an urban slum community of Mumbai. Biol Med 2015;3:3-6.

22. Shivraj BM, Vinay BS, Ranganath TS. Prevalence of hypertension and diabetes mellitus at selected urban slums in Bangalore: A cross sectional study. Int J Community Med Public Health 2016;3:74-7.

23. Banerjee S, Mukherjee TK, Basu S. Prevalence, awareness, and control of hypertension in the slums of Kolkata. Indian Heart J 2016;68:286-94.

24. Singh AK, Kalaivani M, Krishna A, Aggarwal P, Gupta SK. Prevalence, awareness, treatment, and control of hypertension among elderly persons in an urban slum of Delhi, India. Ind J Med Specialities 2014;5:7-10

25. Acharyya T, Kaur P, Murhekar MV. Prevalence of behavioral risk factors, overweight and hypertension in the urban slums of north 24 Parganas district, west Bengal, India, 2010. Indian J Public Health 2014;58:195-8.

26. Panesar S, Chaturvedi S, Saini NK, Avasthi R, Singh A. Prevalence and predictors of hypertension among residents aged 20-59 years of a slum-resettlement colony in Delhi, India. WHO South East Asia J Public Health 2013;2:83-7.

27. Kumari SM, Batool H, Sreedha M. A study on prevalence of hypertension in urban slum field practice area of Osmania medical college- Hyderabad. Indian J Basic Appl Med Res 2014;4:462-70.

28. Awuah RB, Anarfi JK, Agyemang C, Ogedegbe G, Aikins A. valence, awareness, treatment and control of hypertension in urban poor communities in Accra, Ghana. J Hypertens 2014;32:1203-10.

29. Jo I, Ahn Y, Lee J, Shin KR, Lee HK, Shin C. Prevalence, awareness, treatment, control and risk factors of hypertension in Korea: The Ansan study. J Hypertens 2001;19:1523-32.

30. Joffres MR, Hamet P, Rabkin SW, Gelskey D, Hogan K, Fodor G. Prevalence, control and awareness of high blood pressure among Canadian adults. Canadian Heart Health Surveys Research Group. Can Med Assoc J 1992;146:1997-2005.

31. Khullar A. The Role of Melatonin in the Circadian Rhythm SleepWake Cycle. Psychiatric Times. 2012 Available from: http://www. psychiatrictimes.com/sleep-disorders/role-melatonin-circadianrhythm-sleep-wake-cycle. [Last cited on 2018 Apr 19].

32. Brown GM. Light, melatonin and the sleep-wake cycle. J Psychiatry Neurosci 1994;19:345-53.

33. Pickering TG. The effects of environmental and lifestyle factors on blood pressure and the intermediary role of the sympathetic nervous system. J Hum Hypertens 1997;11:9-18.
34. Brown RE, Basheer R, McKenna JT, Strecker RE, McCarley RW. Control of sleep and wakefulness. Physiol Rev 2012;92:1087-187.

35. Hickie IB, Naismith SL, Robillard R, Scott EM, Hermens DF. Manipulating the sleep-wake cycle and circadian rhythms to improve clinical management of major depression. BMC Med 2013;11:79.

36. Wright KP, Lowry CA, Lebourgeois MK. Circadian and wakefulnesssleep modulation of cognition in humans. Front Mol Neurosci 2012;5:50

37. Nazri SM, Tengku MA, Winn T. The association of shift work and hypertension among male factory workers in Kota Bharu, Kelantan, Malaysia. Southeast Asian J Trop Med Public Health 2008;39:176-83.

38. Asfaw CA, Gebrehiwot EM, Shiferaw S. Effect of shift-work on hypertension among factory workers in Ethiopia. Am J Clin Exp Med 2015;3:142-8.

39. Yeom JH, Sim CS, Lee J, Yun SH, Park SJ, Yoo CI, et al. Effect of shift work on hypertension: Cross sectional study. Ann Occup Environ Med 2017;29:11.

40. Pimenta AM, Kac G, Souza RR, Ferreira LM, Silqueira SM. Night-shift work and cardiovascular risk among employees of a public university. Rev Assoc Med Bras 2012;58:168-77.

41. Oishi M, Suwazono Y, Sakata K, Okubo Y, Harada H, Kobayashi E, et al. A longitudinal study on the relationship between shift work and the progression of hypertension in male Japanese workers. J Hypertens 2005;23:2173-8

42. Morikawa Y, Nakagawa H, Miura K, Ishizaki M, Tabata M, Nishijo M, et al. Relationship between shift work and onset of hypertension in a cohort of manual workers. Scand J Work Environ Health 1999;25:100-4.

43. Buckley JP. Physiological effects of environmental stimuli. J Pharm Sci 1972;61:1175-88.

44. Basner M, Babisch W, Davis A, Brink M, Clark C, Janssen S, et al. Auditory and non-auditory effects of noise on health. Lancet 2014;383:1325-32

45. Konkle AT, Keith SE, Namee JP, Michaud D. Chronic noise exposure in the spontaneously hypertensive rat. Noise Health 2017;19:213-21.

46. Westman JC, Walterst JR. Noise and stress: A comprehensive approach. Environ Health Perspect 1981;41:291-309.

47. Stokholm ZA, Bonde JP, Christensen KL, Hansen AM, Kolstad HA. Occupational noise exposure and the risk of hypertension. Epidemiology 2013;24:135-42.

48. Chapman CR, Tuckett RP, Song WC. Pain and stress in a systems perspective. J Pain 2008;9:122-45

49. Spreng M. Possible health effects of noise induced cortisol increase. Noise Health 2000;2:59-63.

50. Sudo N, Chida Y, Aiba Y, Sonoda J, Oyama N, Yu XN, et al. Postnatal microbial colonization programs the hypothalamic-pituitary-adrenal system for stress response in mice. J Physiol 2004;558:263-75.

51. Osha.gov. Occupational Safety and Health Administration. OSHA. 2016. Available from: https://www.osha.gov. [Last cited on 2018 Apr 20].

52. Shrestha A, Shiqi M. Occupational noise exposure in relation to hypertension: A cross-sectional study in the steel factory. Occup Med Health Aff 2017;5:266.

53. Pang LJ, Chen LZ, Fu BY. Prevalence and influence factors of hypertension among mechanic factory workers. Zhong Nan Da Xue Xue Bao Yi Xue Ban 2005;30:276-9.

54. Talbott EO, Gibson LB, Burks A, Engberg R, McHugh KP. Evidence for a dose-response relationship between occupational noise and blood pressure. Arch Environ Health 1999;54:71-8.

55. Chang TY, Liu CS, Hwang BF, Hsieh HH, Bao BY, Chen CJ, et al. Acute effects of noise exposure on 24-h ambulatory blood pressure in hypertensive adults. J Hypertens 2015;33:507-14.

56. Lang T, Fouriaud C, Jacquinet-Salord MC. Length of occupational noise exposure and blood pressure. Int Arch Occup Environ Health 1992;63:369-72.

57. Parvizpoor D. Noise exposure and prevalence of high blood pressure among weavers in Iran. J Occup Med 1976;18:730-1. 